\title{
LAS APORTACIONES DE JESÚS TIMOTEO ÁLVAREZ A LAS CIENCIAS DE LA COMUNICACIÓN: ESTUDIO DE SUS 40 AÑOS DE PRODUCCIÓN ACADÉMICA (1978-2018)
}

Jesús Timoteo Álvarez' Main Contributions to the Communication Sciences: A Study of a 40-year Academic Career (1978-2018)

DOI: https://dx.doi.org/10.12795/RiHC.2020.i14.09

Recibido: 26/04/2020

Aceptado: 27/04/2020

Publicado: $15 / 06 / 2020$

Ángel-Luis Rubio-Moraga

ORCID (iD) 0000-0002-3943-846X

Universidad Complutense de Madrid, España

alrubio@ucm.es

Francisco Cabezuelo-Lorenzo

ORCID (i) 0000-0002-9380-3552

Universidad Complutense de Madrid, España

fcabezuelo@ucm.es

Andrea Donofrio

ORCID (D) 0000-0003-4921-060X

Universidad Complutense de Madrid, España

adonofri@ucm.es

Como citar este artículo: Rubio-Moraga, Ángel-Luis, Cabezuelo-Lorenzo, Francisco, y Donofrio, Andrea (2020): “Las aportaciones de Jesús Timoteo Álvarez a las ciencias de la comunicación: estudio de sus 40 años de producción académica (1978-2018)", en Revista Internacional de Historia de la Comunicación, (14), ISSN 2255-5129, pp. 193-212. 
Resumen: Este trabajo rescata de repositorios nacionales e internacionales la producción académica del catedrático Jesús Timoteo Álvarez Fernández en sus años de actividad docente e investigadora entre 1978 hasta su muerte en 2018 con el fin de clasificar su obra, ponerla en valor y mostrar la validez de su legado a nuevas generaciones de investigadores/as en Ciencias de la información y de la Comunicación. Aplica métodos cuantitativos y cualitativos basados en el análisis bibliográfico y cienciométrico. La investigación concluye que la obra del autor analizado guarda un equilibrio proporcionado entre libros, colaboraciones en obras colectivas y artículos. Se puede clasificar su obra en dos grandes áreas: la Historia de la Comunicación Social y la Comunicación Estratégica o Comercial. Finalmente, destaca el carácter internacional de su legado, con traducciones al inglés, portugués e italiano, además de su profunda influencia en las universidades hispanoparlantes de América.

Palabras clave: Producción bibliográfica; Jesús Timoteo Álvarez Fernández; Universidad Complutense de Madrid; Historia de la Comunicación Social; Sociedad de la Información.

\begin{abstract}
This article rescues Professor Jesús Timoteo Álvarez Fernández' academic production from academic and national databases. It covers his teaching and research activity between 1978 and his death in 2018. This research tries to classify his works, put it in value and show the validity of his legacy to new generations of researchers in the fields of Mass Media and Communication Studies. The methodology applies quantitative and qualitative methods based on bibliographic and scientometric analysis. This paper concludes that there is a proportionate balance between books, book chapters and academic articles among the time. Jesús Timoteo Alvarez's work can be classified into two main fields which are the History of Social Communication and Strategic or Commercial Communication. Finally, this paper underlines the international character of his legacy thanks to several translations into English, Portuguese and Italian, as well as his deep influence on Latin American universities.
\end{abstract}

Keywords: Academic Literacy; Jesús Timoteo Álvarez Fernández; Complutense University; History of Social Communication; Information Society.

\title{
1 Introducción
}

Jesús Timoteo Álvarez Fernández ha sido uno de los académicos más destacados en la docencia e investigación en el mundo de las Ciencias de la Comunicación y de la Información en el último medio siglo, desde 1978, año de publicación sus primeros trabajos académicos, hasta su inesperado fallecimiento el viernes 14 de diciembre 2018. Jesús Timoteo o Timoteo sin más, como era conocido en los entornos académicos y profesionales, fue catedrático de Historia del Periodismo, en el Departamento de Historia de la Comunicación Social y después, con la reforma y fusión departamental, del nuevo Departamento de Periodismo y Comunicación Global, fruto de la unión los antiguos departamentos de Periodismo I (Análisis del Mensaje Informativo), Periodismo II (Empresa Informativa) e Historia de la Comunicación Social. En las citadas tres áreas de las Ciencias de la Información y de la Comunicación, él tenía mucho que aportar por 
su trayectoria personal, profesional y universitaria, más allá de los estancos, cajones y etiquetas académicas. Este trabajo compilatorio a modo de homenaje trata de aunar y repasar toda su producción académica para analizarla, ver sus principales aportaciones y darla conocer a nuevas generaciones de docentes e investigadores españoles e internacionales con el fin de poner en valor su legado.

Jesús Timoteo Álvarez Fernández, nacido en 1948, fue conferenciante en universidades de casi toda España y también invitado a impartir conferencias en otros países de Europa y América. Empezó a dar clase en la UCM en 1976. Además de su trabajo como catedrático en la Complutense, cátedra a la que accedió en 1987, su gran capacidad de trabajo le hizo también tener otros cargos de responsabilidad, tanto ejecutivos como honoríficos. En el plano internacional sus colaboraciones fueron especialmente intensas con Portugal e Italia. Fue nombrado Doctor Honoris Causa y Profesor Honorario en la Escola Superior de Comuniçao Social de la Universidad Politécnica de Lisboa y miembro del patronato para Escuelas Superiores de Comunicación de Portugal. En la Pontificia Università Lateranense (PUL) de Roma, entre 1966 y 1970, Jesús Timoteo Álvarez estudió Teología y Filosofía con especialidad en Patrística, el estudio del cristianismo de los primeros siglos y padres de la Iglesia, que abarca desde el fin del cristianismo primitivo hasta el siglo VIII. Después se licenció en Historia (especialización en Historia Contemporánea) por la Universidad Complutense de Madrid, en 1974. Entre los años 1975 y 1979 se volcó en su Doctorado en Historia de la Comunicación Social.

Durante sus varias décadas de carrera universitaria ocupó cargos de gestión, fue vicedecano de la Facultad de Ciencias de la Información, bajo el decanato del profesor Ángel Benito Jaén, y responsable de la publicación institucional Tribuna Complutense, en los mandatos del rector Rafael Puyol Antolín. En el ámbito de la investigación desarrolló su carrera sobre todo el campo de la Historia de la Comunicación Social, en la primera parte de su carrera universitaria, y en una segunda etapa se volcó más hacia la industria de la comunicación y del entretenimiento. Sus últimos años los pasó centrado en el estudio de la neurocomunicación, tema en el que fue pionero en España. Así, entre 2013 y 2015 , en la recta final como profesor activo antes de pasar a emérito, lideró el exitoso proyecto estatal de I+D titulado Neurocomunicación Social: aplicaciones al Sector e Industria de la Comunicación de los resultados de las Neurociencias y de la Teoría de Redes, financiado por el Ministerio de Economía, dentro del Plan Nacional de I+D+l. También durante sus últimos años fue responsable de otro proyecto de investigación sobre Monetización de Intangibles: Valoración y adecuación a Balance de los Activos Intangibles en las Organizaciones, con financiación privada que se desarrolló entre 2014 y 2017. Del mismo modo, junto con la catedrática María Antonia Paz Rebollo, lideraba el grupo de investigación complutense "Historia y estructura de la comunicación y del entretenimiento", aún hoy vigente y activo. 
En su faceta docente, Jesús Timoteo Álvarez cubrió todas las áreas de la docencia universitaria, en grado (diplomatura, licenciatura y los nuevos grados adaptados al Espacio Europeo de Educación Superior) y posgrado (títulos propios, máster y doctorado). Tal y como recuerda su amigo Octavio Uña, profesor emérito de la Universidad Rey Juan Carlos (URJC) y presidente de la Asociación Castellano-Manchega de Sociología (ACMS), "colaboró sin fisuras, y de manera entusiasta, participando en tribunales de tesis doctorales, en másteres, en conferencias, congresos y demás actividades". Además, Uña recuerda que "fue un socio magnánimo y brillante [de la ACMS], una grandísima persona, un excelente amigo al que echaremos de menos", quien se unió a los textos de recuerdo también publicados por otros académicos como José Carlos García Fajardo (U. Complutense) o Ramón Reig (U. Sevilla), entre otros.

En el ámbito asociativo destaca su labor al frente de la creación en 1992 de la Asociación de Historiadores de la Comunicación (AsHisCom) de la que siempre fue un miembro activo, además de su primer presidente, entre 1992 y 1995. La AsHisCom le rindió un sentido homenaje en su XVI congreso, celebrado en septiembre de 2019 en la Universidad de Santiago de Compostela (USC).

Jesús Timoteo Álvarez supo aplicar sus profundos conocimientos teóricos del mundo de la comunicación social al ámbito de los negocios y la empresa privada y fue socio consultor de la firma Consultores QuantumLeap de Comunicación, desde su creación en 1994. Era su presidente honorífico en el momento de su fallecimiento en diciembre de 2018. QuantumLeap, con sede en Madrid, llegó a trabajar con oficinas delegadas en Barcelona, Valencia, Lisboa, Bogotá, Buenos Aires, México y Sao Paulo (www.cqlp.es). Jesús Timoteo Álvarez estaba considerado como un gran experto de larga trayectoria y reconocido prestigio en relaciones con medios, gestión de la comunicación y en marketing político. Desde QuantumLeap desarrolló actividades y servicios de comunicación en muchos sectores, con especial incidencia en el mundo de la energía y las empresas petrolíferas, la industria del turismo, distribución, comunicación y nuevas tecnologías. Además, participó frecuentemente en equipos de comunicación política y electoral. Entre los clientes a los que prestó servicio durante tres décadas se encontraban grandes corporaciones globales (Coca-Cola, British Petroleum, Electricitè de France-EDF, Banco Santander, Herbalife, Enel) y locales en Europa (Indesit, Gaz de France) o españolas (Xacobeo, Ciudad de las Artes y las Ciencias de Valencia, Terra Mítica, Presidencia de Gobierno de España, la Secretaría de Estado de Turismo, o los gobiernos autonómicos de Madrid, Galicia o la Comunidad Valenciana, entre otros).

Fue fundador y presidente del Instituto de Pensamiento Estratégico "UCM-Think-Com" y de la asociación "Think Tank" de analistas y profesionales de consultoría estratégica. Fue el responsable del grupo de Investigación reconocido como grupo de I+D con sede en la Complutense de Madrid (www.thinkcom.es). Entre 1972 y 1982, antes de 
dedicarse a QuantumLeap, trabajó como periodista de agencias para la United Press International (UPI) y Radiotelevisión Española (RTVE).

Además, Jesús Timoteo Álvarez participó en multitud de actividades de todo tipo, deportivas, asociativas, de voluntariado, patronazgos e iniciativas privadas y públicas con fines sociales y culturales -que no se recogen en este trabajo- pero que van más allá del ámbito académico, siendo además un lector voraz y apasionado de la información de actualidad, tanto nacional como internacional, en todas las áreas, ya fueran políticas, deportivas, culturales o sociales.

\section{Metodología}

Este trabajo se centra solo en analizar las aportaciones académicas y toma como bases para su estudio y construcción toda la producción de monografías o libros propios escritos como autor único o en coautoría por Jesús Timoteo Álvarez Fernández, sus capítulos en obras colectivas, artículos en revistas académicas y científicas, informes universitarios, tesis doctorales dirigidas y obras coordinadas o editadas por él en solitario o en compañía con otros editores/as y/o coordinadores/as.

Para ello, se han usado las bases de datos Dialnet Plus (Universidad de La Rioja), el catálogo CISNE de la Universidad Complutense de Madrid y la base de datos TESEO (Ministerio de Ciencia e Innovación y Ministerio de Universidades). La obra de Jesús Timoteo Álvarez se encuentra registrada en los catálogos de la Biblioteca Nacional de España (BNE), en la Librería del Congreso de los Estados Unidos de América, en la base de datos Identifiants et Référentiels pour l'enseignement supérieur et la recherche (IdRef) de Francia, en el Fichero de Autoridades Virtual Internacional (VIAF) y WorldCat. Del mismo modo, su obra estaba catalogada en ISNI (0000 00011795 1919) y ORCID (0000-0003-0479-1738). La investigación se apoya además en las webs de Todocolección.net, TodosTusLibros.com, Iberlibro.com y Amazon, tanto en su web internacional como en las versiones para España, Italia y Portugal. Del mismo modo, han resultado muy útiles las publicaciones digitales periódicas de homenaje y las webs y bases de datos propias de varias universidades de Europa e Hispanoamérica. Todos estos recursos han sido usados para la compilación de su obra y posterior análisis. Ninguno de estos recursos es completo y todos contienen errores de catalogación, transcripción, ausencias y/o erratas, por lo que esta investigación ha cruzado todas las obras de todas las bases de datos disponibles hasta depurarlas y conseguir las referencias concretas y precisas de autorías/coautorías, títulos, fechas, años y editoriales. Del mismo modo, también se ha tomado como punto de partida la compilación bibliográfica preparada a modo de exposición-homenaje por la Biblioteca de la Facultad de Ciencias de la Información de la Universidad Complutense de Madrid 
(UCM) que culminó con un acto-homenaje con testimonios que le rindió la universidad el 8 de mayo de 2019 organizado por el Departamento de Periodismo y Comunicación Global. Por último, metodológica y bibliográficamente, cabe destacar que, conforme a las normas de esta revista, en este trabajo, se presentan las citas abreviadas dentro del texto y las referencias bibliográficas al final del original por orden alfabético de acuerdo con la norma UNE- 50-104-94.

\section{Análisis y resultados}

La producción académica de Jesús Timoteo Álvarez se concentra en algunos libros de mucho éxito, capítulos o colaboraciones en obras colectivas, sobre todos libros de homenaje y libros compilatorios, muchos de ellos fruto de congresos, jornadas y actas, y de artículos en revistas académicas especializadas en el ámbito de las Ciencias de la Información, sobre todo del área de la Historia de la Comunicación Social. Este trabajo no cubre sus publicaciones privadas para el mundo de la empresa y los negocios en su faceta de consultor. La obra de Jesús Timoteo Álvarez está mayoritariamente presente en lengua española, pero a diferencia de la media de académicos españoles de su generación, sí que cuenta con una notable producción traducida y publicada en inglés, italiano, portugués y gallego.

\subsection{Autoría y coautoría de libros}

Como autor de monografías, Jesús Timoteo Álvarez desarrolló dos líneas de investigación diferentes, que coinciden además con el cambio de siglo. Todas sus publicaciones de la década de los años ochenta y noventa del siglo XX están centradas en la Historia del Periodismo y de la Comunicación Social. Su obra propia del siglo XXI casualmente cambia con el milenio y se centra en los temas ligados a la comunicación empresarial.

Su primer libro Restauración y prensa de masas: los engranajes de un sistema (18751883), publicado en 1981 por EUNSA, el servicio de publicaciones de la Universidad de Navarra, es fruto de su tesis doctoral defendida en 1979. En esta obra ya analiza las relaciones entre el poder y los medios de comunicación en el último cuarto del siglo XIX en España. Este binomio o eje poder-prensa será una constante temática en toda su producción. 


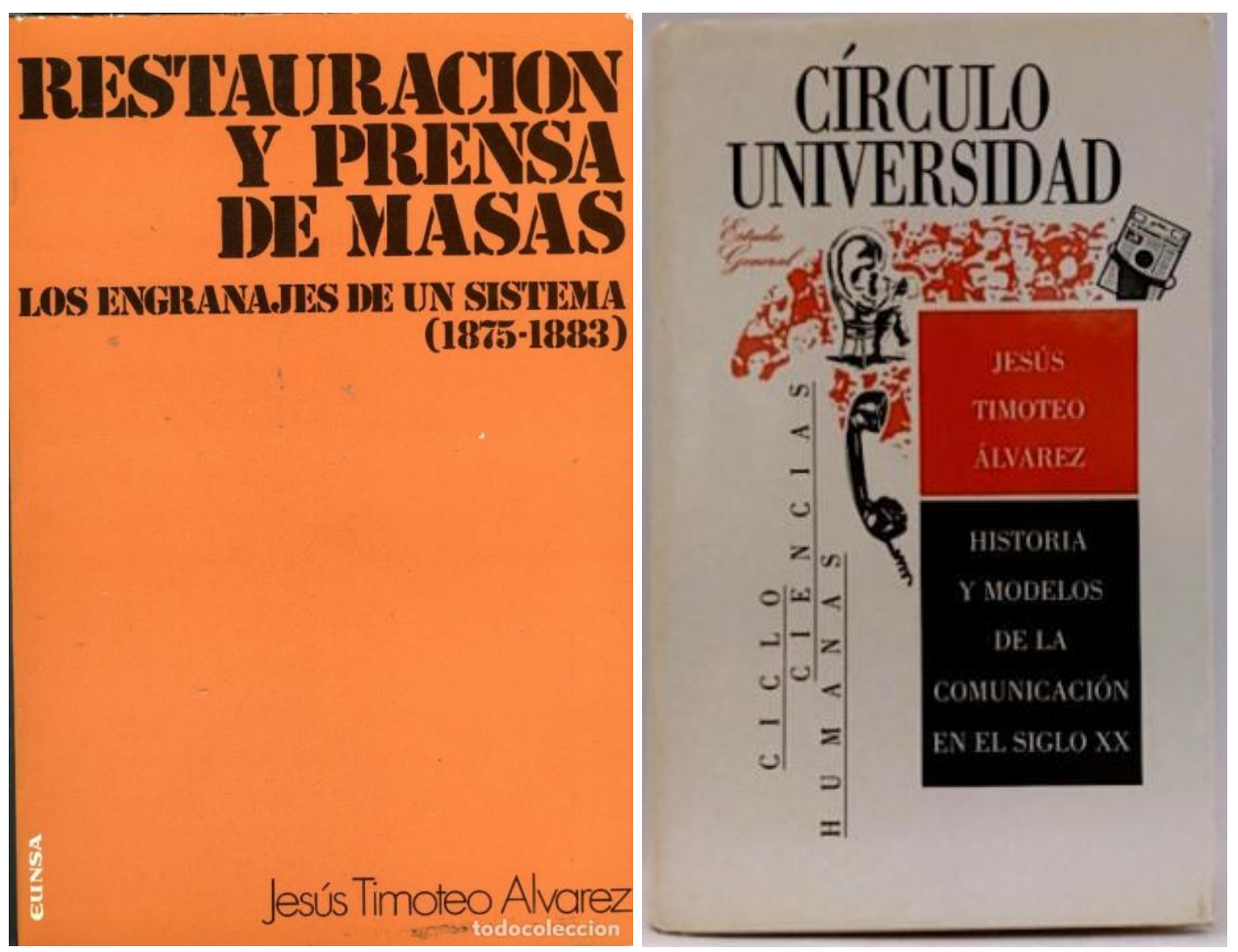

Portada del primer libro de Jesús Timoteo, Restauración y prensa de masas (Eunsa, 1981) y de una de las versiones de Historia y modelos de la comunicación en el siglo XX de Círculo de Lectores (1988). (Fuente: Todocolección.net e Iberlibro.com)

Centrado también en la Historia del Periodismo y de la Comunicación Social, como manual y soporte además para la docencia, Jesús Timoteo Álvarez publicó en 1985 uno de sus manuales más exitosos, Del viejo orden informativo a través de la propia Universidad Complutense. El éxito fue tal que inmediatamente fue editado y actualizado, con una nueva publicación en 1991 con el título Del viejo orden informativo: introducción a la historia de la comunicación, la información y la propaganda en Occidente, desde sus orígenes hasta 1880, por la editorial Actas. Hoy, casi 20 años después sus aportaciones sobre los orígenes del protoperiodismo o periodismo manuscrito y primeros siglos de vida del periodismo industrial, la propaganda e información social siguen estando plenamente vigentes. Continuando la línea iniciada con su tesis y primera obra, en 1987, en colaboración con Victoria María de Diego Vallejo, publica La prensa económica y financiera, 1875-1940: fuentes hemerográficas para la historia de la economía y la hacienda en España, editado como libro con el patrocinio del Ministerio de Hacienda del momento.

Del mismo modo, también en ese mismo año 1987, como continuación de su exitoso Del viejo orden informativo, Jesús Timoteo Álvarez se embarcó en el reto de escribir otra obra que contara la historia de los medios de comunicación desde el nacimiento de la sociedad obrera, urbana y de masas en la recta final del siglo XIX hasta el final del siglo $X X$. De este modo, ese año se publicaba Historia y modelos de la comunicación del siglo $X X$, probablemente su trabajo con mayor eco y repercusión en la academia, cuya primera edición corrió a cuenta de la editorial Ariel. Dado el éxito, un año más tarde, en 
1988, tuvo una nueva edición esta vez publicada bajo el sello de Círculo de Lectores. Ya en nuestro siglo, con cambio de milenio incluido, esta obra fue actualizada y volvió a circular otra vez en la nueva versión titulada Historia y modelos de la comunicación en el siglo XX: con proyecciones al siglo XXI, en esta ocasión publicado por la Editorial Universitas, con la que Jesús Timoteo Álvarez sacaría casi todos sus últimos trabajos académicos.

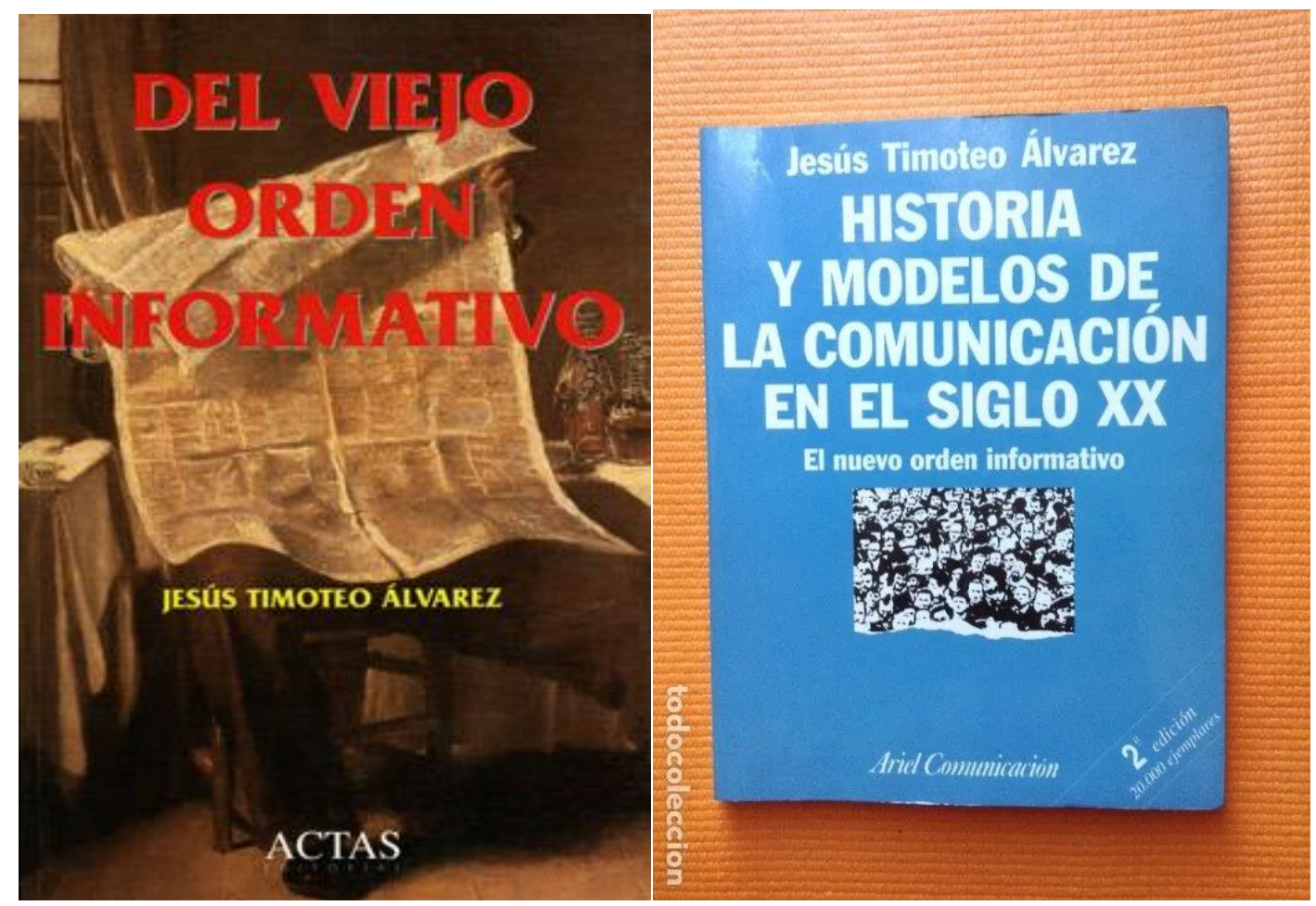

Ejemplares de Del viejo orden informativo (Actas) e Historia y Modelos de la Comunicación en el siglo XX: el nuevo orden informativo (Ariel). Fuente: Todocolección.

Para completar la investigación en Historia del Periodismo y de la Comunicación Social, y con vistas a crear también de este modo libros de referencia y manuales para los nuevos planes de estudio que se implementarían años más tarde en 1995 en la Facultad de Ciencias de la Información, donde habría una amplia oferta de materias optativas, Jesús Timoteo Álvarez, junto con César Aguilera, publicó en 1987 el libro Historia de los medios de comunicación en España: periodismo, imagen y publicidad (1900-1990), también con la editorial Ariel. En 1992, junto con Enrique Ríos Vicente y Ascensión Martínez Riaza, publicó Historia de la Prensa Hispanoamericana, editado por la Fundación Mapfre. Con todo este bloque de publicaciones puede estudiarse perfectamente el corpus teórico de la Historia del Periodismo Español, Iberoamericano y Universal. Sus libros se mantienen hoy en día entre la bibliografía y lecturas obligatorias y/o recomendadas de materias ligadas al ámbito de la Historia de la Comunicación y de la Propaganda. 


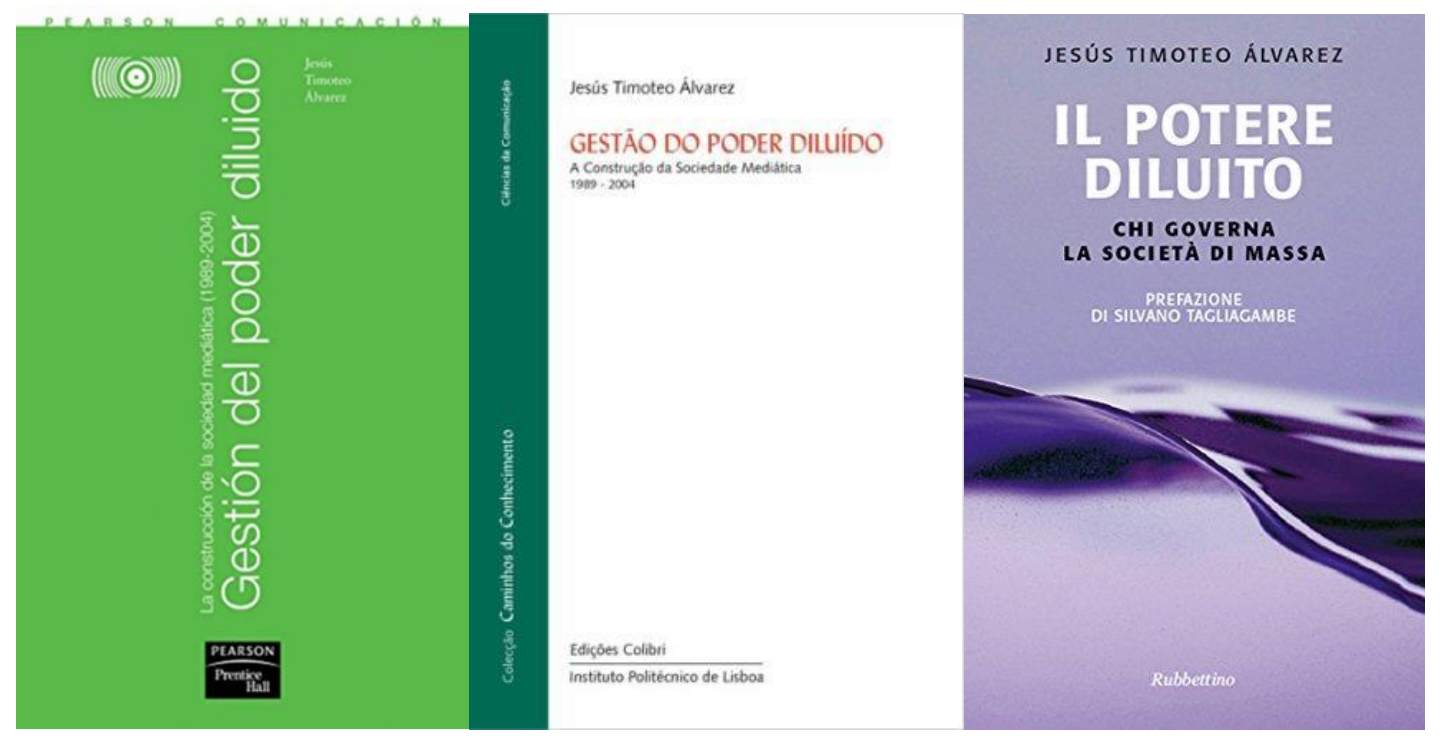

Portadas de Gestión del poder diluido, en su versión española, portuguesa e italiana. (Fuente: Amazon)

En el año 2005 Jesús Timoteo Álvarez publicó con la prestigiosa editorial internacional Pearson/Prentice Hall su obra Gestión del poder diluido: la construcción de la sociedad mediática (1989-2004), editada también en portugués con el título Gestao do poder diluído: a construçao da sociedade mediática 1989-2004 por Ediçoes Colibrí-Instituto Politécnico de Lisboa, y en italiano bajo el título de Il potere diluito: Chi governa la società di massa, publicada en 2011 por la editorial transalpina Rubbettino. La edición italiana contaba con una prefación escrita por el reconocido filosofo Silvano Tagliagambe. Esta obra es, hasta cierto punto, una continuación de sus trabajos previos sobre el devenir histórico de la comunicación social siempre desde una órbita empresarial, de poder y negocios, en esta ocasión marcada también por el peso de los cambios propios de la tecnología que abocaron el cambio de siglo y milenio gracias a la implantación de la actual sociedad digital.

En esta línea de preocupación por el mercado de la comunicación, sus estructuras y la comunicación empresarial, su último libro en español sobre dicha temática fue Manejo de la comunicación en las organizaciones: espacios, herramientas y tendencias en la gestión de negocios, de 2012, publicado por la editorial madrileña Díaz de Santos. “El actual capitalismo, definido como capitalismo financiero, es paralelamente capitalismo reputacional", afirmaba en esta obra Jesús Timoteo Álvarez, a la vez que añadía que estábamos ante "un mundo virtual lleno de signos y productos de futuro más que de realidades y presente en el cual todo es cuestión de fiabilidad, credibilidad, crédito y confianza".

Durante los últimos años de su vida, Jesús Timoteo Álvarez se dedicó a la investigación y publicación de avances en materia de neurocomunicación y de la neuropolítica. De esta época y temática destacan varios trabajos. Sus descubrimientos y los de su equipo de trabajo fueron publicados en el volumen Neurocomunicación. Gestión de la 
Comunicación Social basada en Neurociencias, publicado en un trabajo de 214 páginas en 2013 con la madrileña editorial Fragua. Le seguirían ampliaciones y ediciones internacionales en italiano e inglés. En el país transalpino se publicó el trabajo de 292 páginas titulado Neurocomunicazione. Applicazioni delle scoperte neuroscientifiche alle scienze e all'industria della comunicazione, publicado por Aracne Editrice en Italia en 2015. Y así también llegó su último libro publicado en el extranjero, que fue en inglés, apareció en 2017 y se tituló Social Neurocommunication. Applying the findings from Neurosciences and Network Theory to the Science and Communication Industry (Media XXI, 2017).

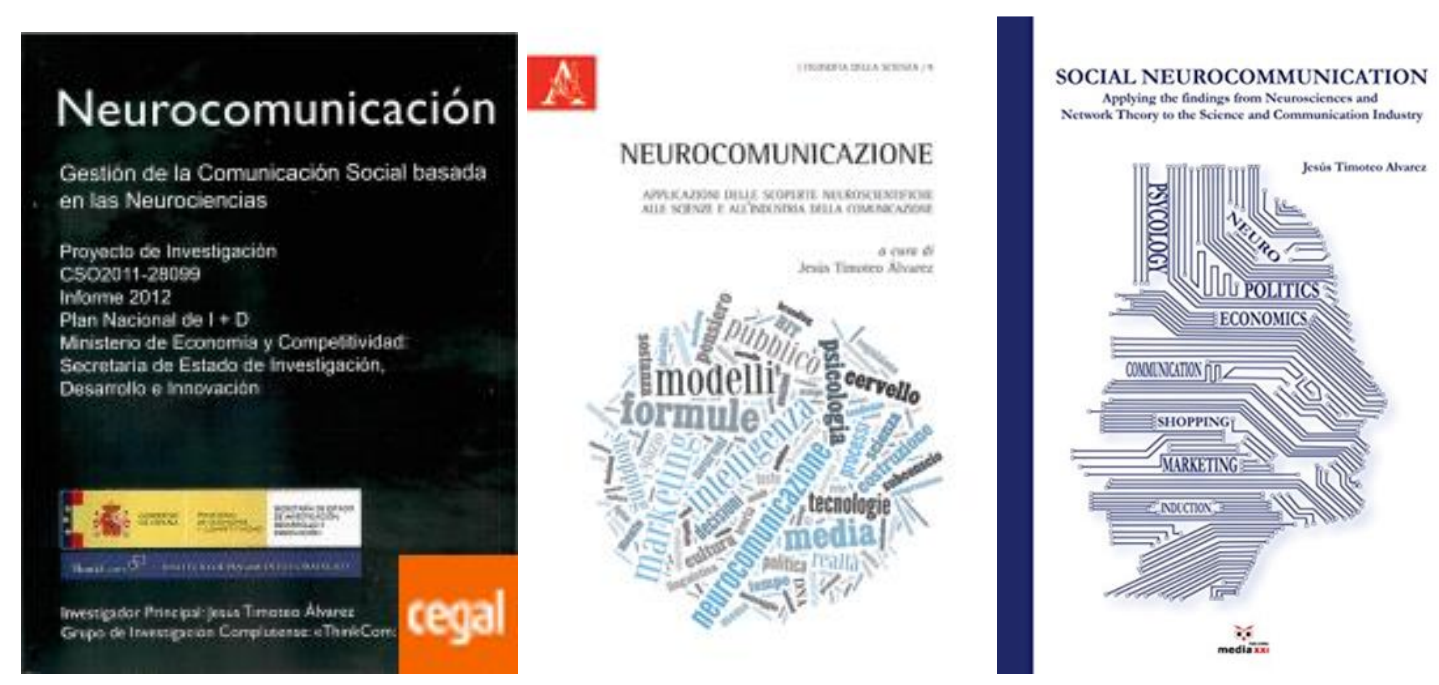

Portadas de sus aportaciones académicas sobre neurocomunicación en sus versiones española, portuguesa e italiana. (Fuentes: TodosTusLibros.com; Aracne Editrice \& Amazon.com)

Su última obra en esta línea fue el trabajo en soporte electrónico titulado El juego real de la singularidad humana. Predicción de comportamientos y toma de decisiones en el cerebro coral, junto con Víctor V. Fernández Bendito y Mercedes Valiente López, publicado en mayo de 2018 por la Fundación General de la Universidad Politécnica de Madrid (UPM).

\subsection{Coordinación y edición de obras conjuntas con otros/as autores/as y editores/as}

La producción bibliográfica de Jesús Timoteo Álvarez no se limita a sus obras en solitario en su calidad de autor y/o coautor. También se dedicó a coordinar obras en las que ejerció el rol de editor, tanto en el ámbito histórico como en el empresarial. En 1987 coordinó el libro titulado Prensa obrera en Madrid, 1855-1936, editado por la Consejería de Cultura de la Comunidad de Madrid. En 1989, junto con las profesoras María Teresa Martínez de Sas, María Ángeles Pérez Samper, Ingrid Schulze y Mercedes Villanova, coordinó el libro-homenaje titulado Haciendo historia. Homenaje al profesor Carlos 
Seco, publicado por la Facultad de Ciencias de la Información de la Universidad Complutense de Madrid (UCM) y la Facultat de Geografía i Història de la Universitat de Barcelona (UB). Este libro contó además con una edición posterior de la UB.

También como editor fue responsable de la obra Muchas voces, un mercado. La industria de la comunicación en Iberoamérica. Perspectivas, publicado por la editorial Universitas en el año 2010. Cinco años más tarde publicaría, también como editor, junto con Gustavo Matías-Clavero, Eduardo Buxaderas-Sánchez y Sonia-Aránzazu FerruzGonzález, la obra titulada Los intangibles en el valor de las empresas. El negocio de Fausto, editada por Díaz de Santos. "Es probable que estemos cumpliendo el sueño de Fausto y que seamos capaces de medir el valor contable del "alma" de las organizaciones", afirmaba. "En el año 2015, el cómo hacer y entender los negocios ha cambiado en modo esencial. Las grandes corporaciones están obligadas a adaptarse a un mercado global", escribió en el prólogo de este libro, algo que sigue de total actualidad y es hoy en día igualmente vigente.

El último trabajo en el que aparece como editor-compilador es la obra conjunta titulada Radio 5: el formato "todo noticias" en la radio pública estatal, junto con Eugenio González Ladrón de Guevara y Miguel Ángel Ortiz Sobrino, publicado por la Universidad Francisco de Vitoria (UFV) en 2017.
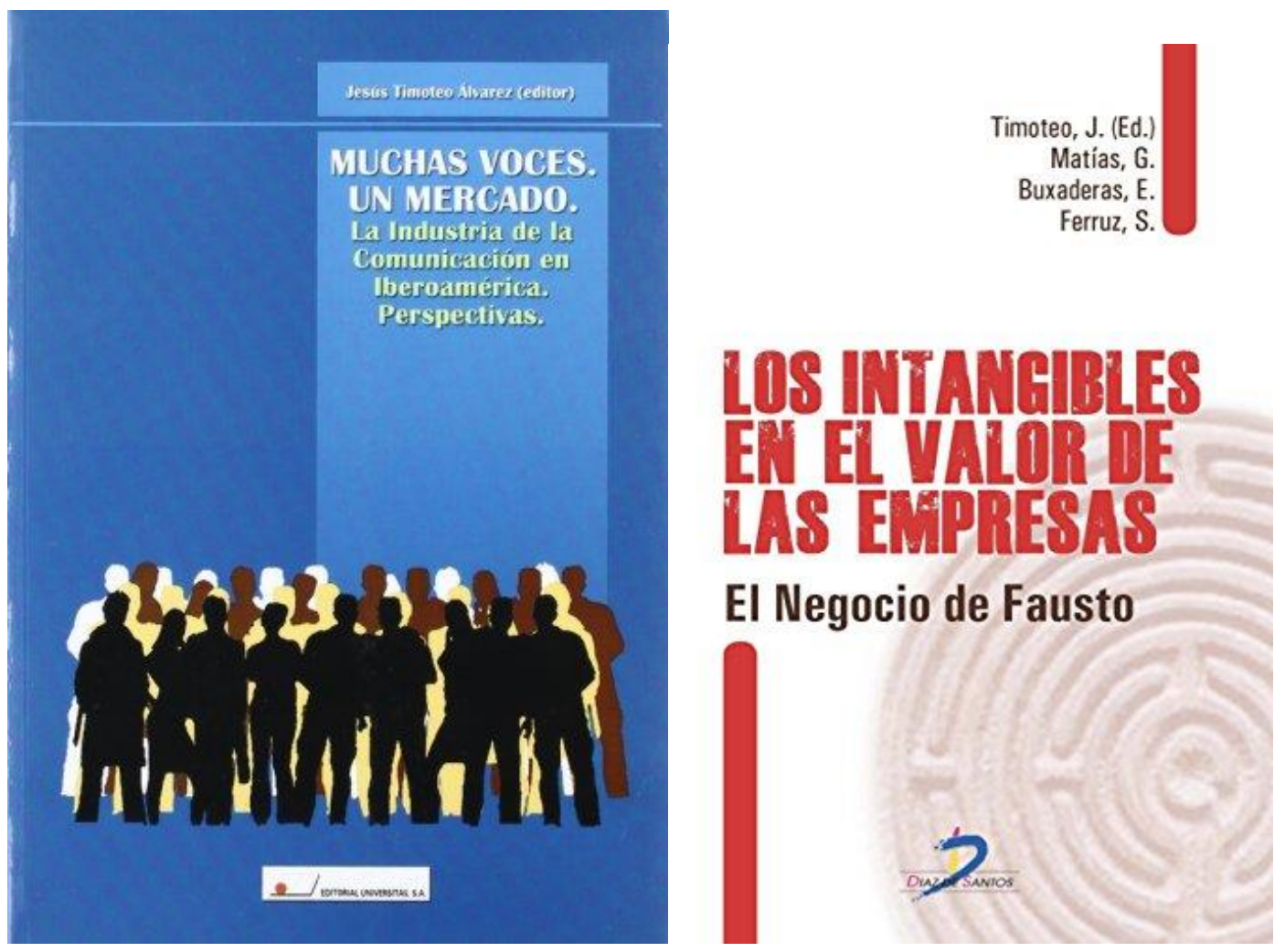

Portadas de Muchas voces, un mercado (Universitas, 2010) y Los intangibles en el valor de las empresas. El negocio de Fausto (Díaz de Santos, 2015). Fuente: TodosTusLibros.com 


\subsection{Capítulos de libros}

Gracias al uso y cruce de datos de diferentes repositorios se han podido compilar un total de 28 capítulos libros o colaboraciones en obras colectivas. Todas las aportaciones están publicadas en castellano, excepto una en gallego. Una de las publicaciones en castellano corresponde, sin embargo, a un Congreso internacional celebrado en Francia. Casi todas ellas $(96,43 \%)$ son de autoría individual, existiendo tan sólo una en coautoría con Julio Montero Díaz (3,57\%).

Del total de capítulos, haciendo un estudio temático por áreas, un total de 15 (53,57\%) corresponden a cuestiones ligadas con la Historia de la Comunicación Social y 11 (46,43\%) al ámbito del Mercado de la Comunicación y Comunicación Empresarial. Otras dos obras sueltas $(7,14 \%)$, por su temática más compleja o diferente, se quedan fuera de estas categorías. Cronológicamente, 12 capítulos corresponden al período 19781999, lo que supone un $42,85 \%$ de su producción frente a los 14 posteriores al año 2000 , lo que equivale a un $57,15 \%$.

De las 28 aportaciones analizadas, destacan por su peculiaridad un total de seis capítulos $(21,42 \%)$ que son el resultado de actas de congresos nacionales o internacionales, como el I Coloquio de Historia Madrileña de 1986, en una obra editada por Luis Enrique Otero Carvajal y Ángel Bahamonde Magro; el congreso francés Le discours de la presse (Actes du 2 e colloque) de noviembre de 1987, con actas editadas por Jean-François Botrel en 1989; el I Encuentro de Historia de la Prensa, coordinado por Carmelo Garitaonandia Garnacho y Manuel Tuñón de Lara, en 1996. Ya en el siglo XX encontramos capítulos fruto de congresos como el Congreso Iberoamericano de Xornalismo Dixital de Santiago de Compostela de noviembre de 2004 o las actas y memoria final del Congreso Internacional Fundacional de la Asociación Española de Investigación en Comunicación (AE-IC) de 2008, igualmente celebrado en Santiago de Compostela.

También destacan entre las aportaciones a obras colectivas las cuatro colaboraciones $(14,28 \%)$ en obras de homenaje a otros profesores ya retirados como es el capítulo de 1988 en homenaje al profesor Carlos Seco Serrano (1989), el homenaje a los profesores José María Jover Zamora y Vicente Palacio (1990), los dos homenajes a Alfonso Braojos (2001 y 2002), o el capítulo que había escrito para el libro homenaje a Octavio Uña, publicado en 2019.

\subsection{Autoría y coautoría de informes}

Jesús Timoteo Álvarez fue autor y coautor de varios informes académicos y científicos propios de sus trabajos de investigación, resultado de varios proyectos tanto de financiación pública competitiva como privada y empresarial. Destaca el trabajo titulado La nueva identidad de la prensa, que hizo en 1988 para la Fundación para el Desarrollo 
de la Función Social de las Comunicaciones (Fundesco) en coautoría con Bernardo Díaz Nosty y Fernando Lallana García bajo la edición de Obdulio Martín Bernal y con el patrocinio de Telefónica.

Sin duda alguna, uno de sus trabajos más curiosos lo encontramos en la obra titulada Castellana 3: una sede histórica, que firmó junto con Secundino José Gutiérrez Álvarez, y José Luis García López, publicado bajo el sello editorial del mismísimo Boletín Oficial del Estado (BOE), en el año 2002. Se trata de un trabajo monográfico histórico y cultural sobre la historia y los usos del singular edificio del Palacio de Villamejor, un antiguo complejo residencial situado en el número 3 del Paseo de la Castellana de Madrid, que fue la sede del Gobierno de España desde 1914 hasta 1977, cuando se trasladó al Palacio de la Moncloa.

Jesús Timoteo Álvarez también participó en la autoría o elaboración junto con doce autores más del informe titulado Medios de comunicación e telecomunicacións del Consello da Cultura Gallega publicado por la Xunta de Galicia en 2005 cuyo coordinador fue Aníbal R. Figueiras Vidal.

\subsection{Artículos}

Se han compilado un total de 17 artículos en revistas científicas gracias al uso y cruce de datos de diferentes repositorios. Todas las aportaciones están publicadas en castellano, menos una en inglés, que es coautoría. En el período de 1978 a 1999 encontramos diez artículos (58,82\%) y del 2000 al 2018 un total de siete (41,18\%). Temáticamente, diez corresponden a cuestiones ligadas a la Historia de la Comunicación Social $(58,82 \%)$ y siete al ámbito de la Comunicación Estratégica y Organizacional (41,18\%). Respecto a las revistas que más artículos acogen de Jesús Timoteo Álvarez destacan las vinculadas a la propia institución académica en la que desarrolló su carrera como son: Revista de Ciencias de la Información, Revista de la Universidad Complutense, Historia y Comunicación Social, Anuario del Departamento de Historia, Documentación de Ciencias de la Información, Mediaciones Sociales o Icono 14. Estas aportaciones suman un total de 9 artículos, lo que supone el 52,94\% de su producción en este apartado. Muchas de estas publicaciones forman parte del catálogo de Scopus como Arbor: Ciencia, Pensamiento y Cultura, Historia y Comunicación Social o Icono 14 o del índice Emerging Sources Citation Index (ESCI) de Clarivate Analytics, antigua Web of Science (WoS) como Documentación de Ciencias de la Información (UCM), entre otras. 


\subsection{Tesis doctorales}

Las bases de datos de Teseo, Dialnet y la Universidad Complutense registran un total 24 tesis doctorales dirigidas en España por Jesús Timoteo Alvarez. En este aspecto destaca especialmente su influencia con la comunidad académica portuguesa. Fue durante muchos años el lazo de unión hispano-luso entre la Universidad Politécnica de Lisboa y la Complutense a través de un programa de Doctorado conjunto. De las 24 tesis defendidas, 23 lo fueron en la UCM y una en la Universidad de Sevilla. De esos 24 trabajos, 20 fueron direcciones de tesis en solitario $(83,33 \%)$ frente a cuatro codirecciones $(16,66 \%)$, dos con profesores portugueses (João Paulo de Jesús Faustino (2017) y João de Pina Cabral (2006)) y otras dos con codirección de colegas complutenses (Miguel Ángel Ortiz Sobrino (2016) y María de los Desamparados Guerra Gómez (2000)). Del total de doctorandos de Jesús Timoteo Álvarez Fernández, cuatro portugueses $(16,66 \%)$ leyeron la tesis bajo su dirección/codirección, Maria Duarte Belo, Sandra Marisa Lopes Miranda, André do Couto Sendin y Jorge Alves do Souto. Del total de tesis dirigidas, por sexo, 11 son de doctorandas (42,30\%) y 13 doctorandos $(57,7 \%)$. Temáticamente, un total de 11 tesis corresponden a la temática de Mercado de la Información y Comunicación Corporativa (42,30\%), seis a Historia de la Comunicación Social $(25 \%)$ y otras siete a temas variados encasillables en otros campos diversos (29,20\%). Jesús Timoteo Álvarez fue el director de tesis de otros académicos que posteriormente han desarrollado una amplia carrera universitaria como María Antonia Paz Rebollo, Amparo Guerra Gómez, Juan José Fernández Sanz, Pablo González-Pola o Sara Núñez de Prado Clavell. Cronológicamente, un total de 8 tesis (25\%) corresponden al período $1987-1999$ y 18 (75\%) al 2000-2018.

\section{Conclusiones}

El análisis de la producción académica de Jesús Timoteo Álvarez Fernández demuestra una doble línea temática del autor, la Historia de la Comunicación Social por un lado y, por otro, un amplio campo de lo que podría unificarse bajo el paraguas de la Comunicación Empresarial, Estratégica y Organizacional o Estudios sobre las Empresas de Comunicación y las Industrias culturales. De la misma manera se puede afirmar que es una carrera completa en un equilibrio entre artículos, capítulos de libros y monografías. Sin embargo, el análisis cuantitativo muestra el peso de los libros en la primera mitad de la carrera docente, con varios manuales de Historia de la Comunicación, hasta el año 1999. A partir del año 2000, se incide más en la segunda línea de investigación pero se mantiene también la primera. A partir del año 2008 , con el inicio de la implantación en España de los planes de estudio adaptados al Espacio Europeo de Educación Superior (EEES) y los nuevos sistemas de acreditación del 
profesorado elaborados por la Agencia Nacional de Evaluación y Calidad (ANECA), aumenta en la carrera docente e investigadora el peso de las publicaciones académicas en forma de artículos indexados. Esta nueva realidad no afectó a la carrera ni horizontes académicos de Jesús Timoteo Álvarez, catedrático ya desde 1987. Sin embargo, publicó artículos en revistas de impacto de los índices Scopus y ESCl, aunque sin la presión a la que podrían estar sometidos otros investigadores con menos experiencia. Destaca como gran mérito del autor la capacidad de internacionalización de su obra, publicada además de en español y otras lenguas cooficiales de España, en idiomas como el inglés, el portugués o el italiano, dados sus vínculos con estos países, además de con la América hispanoparlante.

\section{Referencias bibliográficas:}

ALMEIDA-SANTOS, J. A.; CAVADAS-GORMAZ, M. J.; ÁLVAREZ FERNÁNDEZ, J. T. (2017). "Los estrategas y gestores del populismo moderno (Siglos XVI-XVIII)". Historia y comunicación social, 22, 1, pp. 13-29.

ÁlVAREZ FERNÁNDEZ, J. T. y AGUILERA, C. (1989). Historia de los medios de comunicación en España: periodismo, imagen y publicidad (1900-1990). Barcelona: Ariel.

ÁLVAREZ FERNÁNDEZ, J. T. y MONTERO DÍAZ, J. (2003). "Reivindicación del consumo: marketing, imágenes y ocio en la configuración de la sociedad española de masas". En Uría-González, Jorge (Coord.). La cultura popular en la España contemporánea: doce estudios. Madrid: Biblioteca Nueva, pp. 213-234.

ÁLVAREZ FERNÁNDEZ, J. T. (1978). “Elementos para un nuevo modelo del análisis histórico: de la historia del periodismo a la historia total". Revista de la Universidad Complutense, 113, pp. 399-424.

- (1980). “Aproximación a las fuentes y referencias básicas de la historia del periodismo universal”. Documentación de las ciencias de la información, 4, pp. 157-174.

- (1981). Restauración y prensa de masas: los engranajes de un sistema (1875-1883). Pamplona: Eunsa/Universidad de Navarra.

- (1983). "Elementos para una reinterpretación histórica del siglo XX: El caso de la información-propaganda en Gran Bretaña, 1914-1918". Boletín de la Real Academia de la Historia, 180, 1, pp. 149-186. 
- (1983). "La crisis del sector prensa y el nacimiento de una nueva fase en el capitalismo informativo (1960-1975)". Revista de Ciencias de la Información, 6, pp. 313-335.

— (1985). Del viejo orden informativo. Madrid, Universidad Complutense.

- (1986). "Estructura subterránea de la prensa en la Restauración". En Otero-Carvajal, Luis Enrique \& Bahamonde-Magro, Ángel (Coords.). Madrid en la sociedad del siglo XIX. I Coloquio de Historia Madrileña. Volumen I: La ciudad y su entorno; Madrid centro de poder político; Poder económico y élites locales. Madrid: Consejería de Cultura de la Comunidad de Madrid, pp. 229-248.

- (1986). "Propaganda profesional antifrancesa: el caso del Mercurio Britannico en portugués (1798-1800)". Estudios de historia social, 36-37, pp. 155-159.

- (1987). Historia y modelos de la comunicación en el siglo XX: el nuevo orden informativo. Barcelona: Ariel.

- (1988). "Impacto, evaluación y efectos sociales de la reconversión tecnológica en la prensa diaria". Boletín de la Fundación para el Desarrollo de la Función Social de las Comunicaciones (Fundesco), 85, pp. 11-13.

- (1988). Historia y modelos de la comunicación en el siglo XX: el nuevo orden informativo. Barcelona: Círculo de Lectores.

- (1989). “¿Agentes de información o de conocimiento?: El impacto de las NTI en los periódicos". En Botrel, Jean-François (Coord.) Le discours de la presse. Actes du $2 e$ colloque. Rennes: Presses universitaires de Rennes, pp. 63-70

- (1989). "Historia de la comunicación: savia nueva para una historiografía cansada". En VVAA. Haciendo historia. Homenaje al profesor Carlos Seco. Madrid/Barcelona: Universidad Complutense de Madrid-Universitat de Barcelona, pp. 651-664.

- (1989). "La comunicación aplicada en el nuevo ciclo de la historia de la comunicación". Anuario del Departamento de Historia, 1, pp. 13-26.

- (1989). "La información en la era de Franco: Hipótesis interpretativa". Revista de Ciencias de la Información, 6, pp. 11-24.

- (1989). "Propaganda y medios de información en Madrid, 1900-1920". En OteroCarvajal, Luis Enrique \& Bahamonde-Magro, Ángel (Coords.). La sociedad madrileña durante la Restauración. Volumen II. Madrid: Comunidad de Madrid, pp. 267-278

- (1990). "Políticas de información y propaganda en España (1920-1936)". En VVAA. Estudios históricos: Homenaje a los profesores José María Jover Zamora y Vicente Palacio Atard. Volumen II. Madrid: Universidad Complutense, pp. 203-220. 
- (1991). Del viejo orden informativo: introducción a la historia de la comunicación, la información y la propaganda en Occidente, desde sus orígenes hasta 1880. Madrid: Actas.

- (1993). “Conspiración judeo-masónica-comunista: reflexiones primerizas”. En FerrerBenimeli, José-Antonio (Coord.). Masonería y periodismo en la España contemporánea. Zaragoza: Universidad de Zaragoza-Prensas Universitarias de Zaragoza, pp. 261-268.

- (1994). "Los medios de información". En Del-Campo, Santiago (Coord.). Tendencias sociales en España (1960-1990). Volumen 2. Bilbao: Fundación Banco Bilbao Vizcaya (BBVA), pp. 331-346.

- (1994). "Mercado de la información". En Del-Campo, Santiago (Coord.). Tendencias sociales en España (1960-1990). Volumen 3. Bilbao: Fundación Banco Bilbao Vizcaya (BBVA), pp. 99-114.

- (1994). "Un futuro a la carta". En Pizarroso-Quintero, Alejandro (Coord.). Historia de la prensa. Madrid: Fundación Ramón Areces, pp. 575-586.

- (1996). "Conceptos básicos para una Codificación de la Historia del Periodismo o Comunicación". En Garitaonandia-Garnacho, Carmelo \& Tuñón-de-Lara, Manuel (Coords.). La prensa de los siglos XIX y XX metodología, ideología e información. Aspectos económicos y tecnológicos: I Encuentro de Historia de la Prensa. Bilbao: Universidad del País Vasco/Euskal Herriko Unibertsitatea, Servicio de Publicaciones, pp. 21-32.

- (1996). “Opinión pública y propaganda bélica al inicio de la contienda” En De-DiegoGarcía, Emilio (Coord). 1895, la Guerra en Cuba y la España de la Restauración. Madrid: Universidad Complutense, pp. 247-262.

- (1997). "Gestión de la comunicación en las organizaciones consolidadas". Historia y comunicación social, 2, pp. 251-258.

- (1997). "Naciones moribundas: influencia y repercusión de la caída de Filipinas en la opinión española". En El lejano oriente español: Filipinas (siglo XIX). Actas de las Jornadas Nacionales de Historia Militar. Sevilla: Cátedra General Castaños, pp. 739-750.

- (1999). "El signo más del siglo que termina". El Siglo que viene: Revista de cultura, 3940, pp. 6-8.

- (2000). "La evolución del hipersector de comunicación + información". En LagunaPlatero, Antonio (Coord.). La comunicación en los 90: el mercado valenciano. Valencia: Fundación Universitaria San Pablo CEU, pp. 17-27. 
- (2001). "Cartografiando una nueva sociedad: la configuración del mercado de masas en España en torno a 1900". Parias-Sainz-de-Rozas, María del Carmen et alt. Comunicación, historia y sociedad: homenaje a Alfonso Braojos. Sevilla: Universidad de Sevilla, pp. 47-58.

- (2001). "Rendentores irredentos: Los diarios madrileños después del 98". Arbor: Ciencia, pensamiento y cultura, 666, pp. 541-556.

- (2002). "Braojos: el orgullo del Sur". En García-Galindo, Juan-Antonio; GutiérrezLozano, Juan-Francisco \& Sánchez-Alarcón, María-Inmaculada (Coords.). La comunicación social durante el franquismo. Málaga: Diputación Provincial de Málaga, pp. 807-808.

- (2002). "De los orígenes de la prensa de masas en España: otras perspectivas desde el consumo de masas". En VV. AA. Del periódico a la Sociedad de la Información. Madrid: Sociedad Estatal España Nuevo Milenio, pp. 173-188.

- (2004). Negocios en la red Internet. Tendencias en el ciberperiodismo iberoamericano. En Gago-Mariño, Manuel et alt. (Coords.). Ponencias do Congreso Iberoamericano de Xornalismo Dixital, Santiago de Compostela: Universidade de Santiago de Compostela, 217-233.

- (2005). Gestión del Poder Diluido: la construcción de la sociedad mediática 1989-2004. Madrid: Pearson Ed., Madrid, 2005. Traducido al italiano por Ed. Rubbettino, Bari (2007).

- (2006). “Comunicación basura”. Contrastes: Revista cultural, 43, pp. 79-87.

- (2006). "La fuerza civil: parlamentos, medios y opinión en el entorno de poder diluido". Corts: Anuario de derecho parlamentario, 17, 2006, pp. 371-404.

- (2007). "Neurocomunicación. Propuesta para una revisión de los fundamentos teóricos de la comunicación y sus aplicaciones industriales y sociales". Mediaciones sociales, 1, pp. 355-386.

- (2008). "A comunicación estratéxica e a imaxe corporativa nas universidades". En Pena-Rodríguez, Alberto \& Torres-Romay, Emma (Coords.). Comunicación e universidade. Vigo: Universidade de Vigo, pp.17-21.

- (2008). "Entorno mixto para gestión de reputación e intangibles." En FernándezFernández, Maximiliano (Coord.). Comunicación en la sociedad red: la construcción mediática de la realidad. Ávila: Universidad Católica de Ávila, pp. 73-95.

- (2008). "Red social en formato mapa de burbujas. Puerta del futuro en las relaciones con medios: Social network bubble map \& next steps in media relationships". En VVAA. I+C Investigar a comunicación: Investigar la comunicación: Actas y memoria 
final del Congreso Internacional Fundacional $A E-I C$, Santiago de Compostela, CDRecurso electrónico.

- (2009). "Agentes (makers) creadores de la sociedad mediática". En García-Galindo, Juan-Antonio; Vasallo-de-Lopes, María Immacolata \& Vera-Balanza, María Teresa (Coords.). Construir la sociedad de la comunicación. Madrid: Tecnos, pp. 188-195.

- (2009). "Cuatro hechos sobre las televisiones públicas, su pasado y su futuro". En López-García, Xosé; Pereira-Fariña, Xosé \& Rúas-Araújo, José (Coords.). Medios de comunicación públicos: modelos de organización e funcionamento na Sociedade da Información, propostas para a súa reforma. Santiago de Compostela: Edicions Lea, pp. 41-44.

- (2009). "El control político de la información". Herrero, Julio-César (Coord.). Manual de Teoría de la Información y de la Comunicación. Madrid: Universitas, pp. 407428.

- (2009). "Senderos en el bosque: condicionantes y perspectivas de las estrategias de comunicación en la sociedad red". En Ramos-Serrano, Marina; Garrido-Lora, Manuel \& Rodríguez-Centeno, Juan-Carlos (Coords). Publicidad y comunicación corporativa en la era digital. Madrid: Pirámide, pp. 15-50.

- (2010). "La Transición más rupturista: televisión y sus influencias en la sociedad española, 1975-2005”. En Ansón-Anadón, Antonio (Coord.). Televisión y literatura en la España de la Transición (1973-1982). Zaragoza: Institución Fernando el Católico, pp. 231-265.

- (2010). "Los políticos como enemigos: gestión de los external affairs y de las government relations". Icono14, 8, 2, pp. 383-406. https://doi.org/10.7195/ri14.v8i2.265

- (2010). "Triada de espejos: propuesta metodológica para una nueva 'Historia de la Comunicación' a partir de sus relaciones con la Economía y la Política". En Bordería-Ortiz, Enrique; Martínez-Gallego, Francesc-Andreu \& Rius-Sanchís, Inmaculada (Coords.). Política y comunicación en la historia contemporánea. Madrid: Fragua, pp. 17-50.

- (2012). Historia y modelos de la comunicación en el siglo XX: con proyecciones al siglo XXI. Madrid: Editorial Universitas, 2012.

- (2012). Manejo de la Comunicación Organizacional: Espacios, Herramientas y Tendencias en Gestión de Negocios. Madrid: Diaz de Santos.

- (2015). Los Intangibles en el Valor de las Empresas: El Negocio de Fausto. Madrid: Diaz de Santos. 
- (2019). "Previsiones en la niebla: hipótesis sobre estrategias en el mercado del voto". En Lazcano-González, Rafael (Coord.) Intellectum valde ama. Ama intensamente la inteligencia. Homenaje al Profesor Octavio Uña Juárez, Catedrático de Sociología y Filosofía, escritor y poeta. Pp. 1358-1366.

- [Coord.] (2013). Neurocomunicación: Gestión de la Comunicación Social basada en las Neurociencias. Ed. ThinkCom Instituto de Pensamiento Estratégico y Secretaría de Estado de Investigación, Desarrollo e Innovación. Traducido al italiano por Aracne Editrice-Roma (2013) y al inglés por Focus Media XXI (2014).

ÁlVAREZ FERNÁNDEZ, J. T.; GUTIÉRREZ-ÁLVAREZ, S. J.; GARCÍA-LÓPEZ, J. L. (2002). Castellana 3: una sede histórica. Madrid: Boletín Oficial del Estado (BOE).

ÁLVAREZ FERNÁNDEZ, J. T; RÍOS-VICENTE, E.; MARTÍNEZ-RIAZA, A. (1992). Historia de la prensa hispanoamericana. Madrid: Fundación MAPFRE.

ASOCIACIÓN DE HISTORIADORES DE LA COMUNICACIÓN [AsHisCom] (2018). Adiós a nuestro compañero Jesús Timote Álvarez. Disponible en: https://cutt.ly/6yaeJVu. Consulta: 18-03-2020.

BARCIELA, A. (2018). "La muerte de Jesús Timoteo no es una fake news". Galicia Única. Revista digital independiente. https://cutt.ly/xyaeKLw. Consulta: 15-03-2020.

DE DIEGO-VALLEJO, V. M. y ÁLVAREZ-FERNÁNDEZ, J. T. (1985). La prensa económica y financiera, 1875-1940: fuentes hemerográficas para la historia de la economía y la hacienda en España. Madrid: Ministerio de Hacienda.

DÍAZ-NOSTY, B.; MARTÍN-BERNAL, O.; LALLANA-GARCÍA, F.; ÁLVAREZ FERNÁNDEZ, J. T. (1988). La nueva identidad de la prensa: transformación tecnológica y futuro. Madrid, Fundesco.

GARCÍA-FAJARDO, J. C. (2018). "In memoriam de mi gran amigo y compañero Jesús Timoteo Álvarez". Sección "El envés". Ibercampus. Disponible en: https://cutt.ly/XyaeLCg. Consulta: 17-03-2020.

GONZÁLEZ-LADRÓN-DE-GUEVARA, E.; ORTIZ-SOBRINO, M. A.; ÁLVAREZ FERNÁNDEZ, J. T. (Coords.) (2017). Radio 5: el formato "Todo Noticias" en la radio pública estatal. Pozuelo de Alarcón (Madrid): Universidad Francisco de Vitoria.

REIG, R. (2018). "Fallece Timoteo Álvarez". El Correo de Andalucía. Sección Columnas de Opinión: Los medios y los días. Disponible en: https://cutt.ly/qyaeZlu. Consulta: 18-03-2020.

UÑA-JUÁREZ, O. (2018). "Fallece Jesús Timoteo Álvarez, socio histórico y magnánimo". Asociación Castellano-Manchega de Sociología (ACMS). Disponible en: https://cutt.ly/CyaeXsY. Consulta: 20-03-2020. 